\title{
Analytical solutions of stresses and displacements for deep circular tunnels with liners in saturated ground*
}

\author{
Peng-fei $\mathrm{LI}^{\dagger 1,2}$, Qian FANG ${ }^{3}$, Ding-li ZHANG ${ }^{3}$ \\ $\left({ }^{1}\right.$ Key Laboratory of Urban Security and Disaster Engineering, Ministry of Education, \\ Beijing University of Technology, Beijing 100124, China) \\ ( ${ }^{2}$ Beijing Collaborative Innovation Center for Metropolitan Transportation, Beijing 100124, China) \\ $\left({ }^{3}\right.$ Key Laboratory for Urban Underground Engineering of the Education Ministry, Beijing Jiaotong University, Beijing 100044, China) \\ †E-mail: lpf@bjut.edu.cn \\ Received Jan. 15, 2014; Revision accepted Mar. 31, 2014; Crosschecked May 21, 2014
}

\begin{abstract}
To investigate the displacement and stress distributions for deep circular tunnels with liners in saturated ground, an analytical model is proposed. For a deep tunnel with drainage conditions, plane strain conditions at any cross-section of the tunnel and the elastic regime of the linear elasticity for the remaining liner are assumed, while the ground is assumed to be linearly elastic and perfectly plastic with a failure surface defined by the Mohr-Coulomb criterion. The post-yield behavior of the ground follows the non-associated flow rule defined by the dilation angle. To solve the proposed problem, two procedures are presented. An axisymmetric model for a deep circular tunnel with a steady-state seepage condition is considered, and then a simple closed-form analytical solution is obtained with a common theoretical framework for the boundary conditions of a constant total head along the tunnel circumference. Assuming that certain ground displacements along the tunnel circumference have occurred before the installation of the liner, analytical solutions of stresses and displacements are derived with particular emphasis on the seepage and the stress release effect induced by tunnelling. The proposed analytical model is validated by numerical simulation.
\end{abstract}

Key words: Deep tunnel, Seepage force, Plane strain model, Analytical solution, Numerical simulation doi: 10.1631 jzus.A1400023

Document code: A

CLC number: U45

\section{Introduction}

One of the important issues during the construction of deep tunnels in saturated ground is the appropriate design of the tunnel liners. The convergence-confinement method (CCM) has become very popular for tunnel construction throughout the world due to its technical feasibility, safety, and economic competitiveness (Carranza-Torres and and Fairhurst, 2000; Oreste, 2003a; 2003b; González-

\footnotetext{
* Project supported by the National Natural Science Foundation of China (No. 51308012), and the Beijing Natural Science Foundation (No. 3144026), China

(C) Zhejiang University and Springer-Verlag Berlin Heidelberg 2014
}

Nicieza et al., 2008). According to the concept of the CCM, the tunnel liners should be designed to sustain the loads transmitted from the surrounding ground during excavation as well as the seepage forces due to the water flow towards the tunnel, if any (Lee and Nam, 2001; Bobet, 2003; Nam and Bobet, 2006). The effects of seepage force and in-situ stress on displacements and stress distributions for deep tunnels in saturated ground have been investigated by numerous researchers (Schweiger et al., 1991; Lee and Nam, 2001; Bobet, 2001; 2003; Arjnoi et al., 2009; Li, 2011).

Although there are a lot of numerical procedures capable of estimating the ground displacements and liner stresses, analytical solutions are still desirable in direct applications or in the validation and 
verification of numerical models for their advantages of conciseness and convenience (Huangfu et al., 2010).

Analytical solutions of the distribution of the pore pressure in the rock mass for steady seepage of deep tunnles are also obtained in previous studies. For instance, based on the theory of complex potentials, the theory of Cauchy integrals, and of singular integral equations, the steady-state fluid flow solution for fractured porous media was obtained by Liolios and Exadaktylos (2006). They also provided a numerical method for the accurate estimation of pore pressure and pore pressure gradient fields due to specified hydraulic pressure or pore pressure gradient acting on the lips of one or multiple non-intersecting curvilinear cracks in a homogeneous and isotropic porous medium, but there is a fly in the ointment for which they could not provide the complete analytical solutions of displacements and stresses for tunnels in saturated ground.

Complete analytical solutions of displacements and stresses for tunnels in saturated ground are obtained by Bobet $(2001 ; 2003)$ and Nam (2006). These solutions cover different construction processes and ground conditions, including dry or saturated ground, shallow or deep, with or without air pressure, and with or without a gap between the ground and the liner. However, these solutions are restricted to cases where ground displacements are small, since the ground and the liner are assumed to behave elastically.

Based on the assumptions that circular tunnels are excavated in elasto-plastic homogeneous ground under hydrostatic stress conditions, a series of analytical or semi-analytical analyses have been performed (Fenner, 1938; Brown et al., 1983; Carranza-Torres and Fairhurst, 2000; Sharan, 2005; Lee et al., 2000; Fang et al., 2013; Han et al., 2013). All these studies have contributed to the understanding of the surrounding ground-liner interaction mechanism, but the results do not apply to the tunnels in saturated ground.

Considering the effect of seepage forces, ground stresses are obtained by Li et al. (2004) and Liu et al. (2009) for deep circular tunnels in elastic-perfectly plastic material with a Mohr-Coulomb type yield criterion while neglecting the existence of liners. Their studies were complemented by $\mathrm{Lu}$ and $\mathrm{Xu}$
(2009), who proposed an analytical model to solve the stresses for a subsea tunnel with liner. Note that all these studies are not capable of providing the solutions of ground displacements in the plastic zone.

In this study, elasto-plastic plane strain solutions of the stress and displacement distributions around deep circular lined tunnels in isotropic saturated ground due to uniform ground loads and seepage forces are presented. The derivation process for the expression of displacements in the plastic zone is a highlight in this paper. A gap between the ground and the liner, which represents a certain ground displacement along the tunnel circumference occurred before the installation of the liner is also considered. The proposed model is particularly suitable for the investigation of deep circular tunnels excavated in soft saturated ground.

\section{Problem description}

The fundamental objective of this paper is to study the stresses and displacements of tunnels with liners in saturated ground considering the effect of both the seepage force and in-situ stress. To derive the analytical solution for the proposed problem, the following assumptions are made: (1) The circular tunnel is located in a fully saturated, homogeneous and isotropic aquifer subjected to uniform in-situ stress. (2) Plane strain conditions are applicable at any tunnel cross-section. (3) The liner behaves in a linear elastic manner. (4) The ground behaves in an elasticperfectly plastic manner, obeys the linear Mohr-Coulomb yield criterion, and is considered weightless. (5) The water is incompressible, and Darcy's law is applicable. (6) Before the installation of the liner, certain ground displacements along the tunnel circumference have already occurred. Therefore, there is a constant gap between the ground and the liner along the perimeter of the tunnel (Bobet, 2001), which can represent the displacements due to any physical gap, the unsupported tunnel face, the liner construction lag, or the time effect of shotcrete hardening process. For example, the installation delay of the support will inevitably cause certain ground displacements. Moreover, even though the shotcrete lining is installed immediately after the excavation, certain ground displacements will gradually take 
place as the shotcrete hardens (Oreste, 2003b).

A schematic model of the proposed problem is shown in Fig. 1. In this model, $r_{\mathrm{i}}$ is the inner radius of the liner, $r_{1}$ is the outer radius of the liner, and $r_{0}$ is the outer boundary of the problem. In this study, $r_{0}=20 r_{\mathrm{i}}$. The outer boundary is far enough from the inner tunnel boundary, therefore the presence of the outer boundaries have limited impact on the solutions. This method has been adopted by numerous researchers (Bobet, 2003; Li et al., 2004; Nam and Bobet, 2006; Liu et al., 2009). There are no displacement constraints at the boundaries (Nam and Bobet, 2006). Ambient stresses $\sigma_{1}$ and $\sigma_{0}$ are the radial pressures (the tension is positive) at the inner boundary and the outer boundary, respectively. $h_{\mathrm{i}}$ and $h_{0}$ are the water head on the inner boundary and the outer boundary, respectively. $k_{1}$ is the hydraulic conductivity of the liner. $k_{\mathrm{p}}$ and $k_{\mathrm{e}}$ are the hydraulic conductivities of the plastic zone and the elastic zone, respectively. $E_{1}$ and $\mu_{1}$ are the elasticity modulus and the Poisson's ratio of the liner, respectively. $E_{\mathrm{p}}$ and $\mu_{\mathrm{p}}$ are the elasticity modulus and the Poisson's ratio of the ground in the plastic zone, respectively. $E_{\mathrm{e}}$ and $\mu_{\mathrm{e}}$ are the elasticity modulus and the Poisson's ratio of the ground in the elastic zone, respectively. $c_{\mathrm{p}}, \varphi_{\mathrm{p}}$, and $\psi_{\mathrm{p}}$ are the cohesion, the internal friction angle, and the dilation angle of the ground, respectively.

The yield zone radius, $r_{\mathrm{p}}$, the water head on the outer of the liner, $h_{1}$, the water head on the plastic zone, $h_{\mathrm{p}}$, the radial stress at the ground-liner interface, $\sigma$, and the radial stress at the plastic-elastic interface, $\sigma_{\mathrm{p}}$ can be derived by using the seepage and mechanical theory.

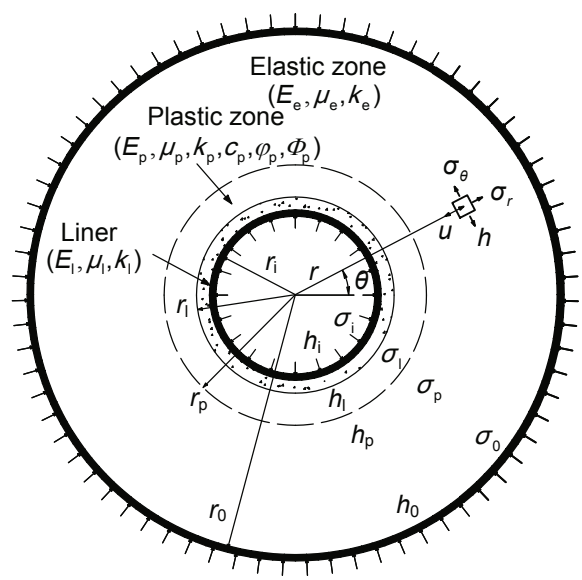

Fig. 1 Schematic illustration of the analytical model
The radial stress, $\sigma_{\mathrm{r}}$, the tangential stress, $\sigma_{\theta}$, the water head, $h$, the displacement, $u$, are the functions of the radial distance from the tunnel center, $r$, and will be given analytically by a theoretical model in this study.

\section{Proposed analytical model}

\subsection{Analytical solutions of the seepage field}

It follows from the symmetry with respect to the axis of the tunnel that the flow is radial, and the discharge vectors at all points are directed toward the center of the tunnel. According to Bear (1972), following the continuity equation, there is

$$
\frac{\mathrm{d}}{\mathrm{d} r}\left(r \frac{\mathrm{d} h}{\mathrm{~d} r}\right)=0,
$$

then

$$
h=C_{1} \ln r+C_{2},
$$

where $C_{1}$ and $C_{2}$ are two integration constants.

The corresponding boundary conditions for the problem are

$$
\begin{array}{ll}
\left.h\right|_{r=r_{\mathrm{i}}}=h_{\mathrm{i}}, & \left.h\right|_{r=r_{\mathrm{i}}}=h_{1}, \\
\left.h\right|_{r=r_{\mathrm{p}}}=h_{\mathrm{p}}, & \left.h\right|_{r=r_{0}}=h_{0} .
\end{array}
$$

Substituting Eq. (3) into Eq. (2), we can obtain:

$$
h= \begin{cases}\frac{h_{\mathrm{i}} \ln \left(r_{1} / r\right)+h_{1} \ln \left(r / r_{\mathrm{i}}\right)}{\ln \left(r_{1} / r_{\mathrm{i}}\right)}, & r_{\mathrm{i}} \leq r \leq r_{1}, \\ \frac{h_{1} \ln \left(r_{\mathrm{p}} / r\right)+h_{\mathrm{p}} \ln \left(r / r_{1}\right)}{\ln \left(r_{\mathrm{p}} / r_{1}\right)}, & r_{1}<r \leq r_{\mathrm{p}}, \\ \frac{h_{\mathrm{p}} \ln \left(r_{0} / r\right)+h_{0} \ln \left(r / r_{\mathrm{p}}\right)}{\ln \left(r_{0} / r_{1}\right)}, & r_{\mathrm{p}}<r \leq r_{0} .\end{cases}
$$

Let $Q_{\mathrm{l}}, Q_{\mathrm{p}}$, and $Q_{\mathrm{e}}$ be the water discharge through the ground in the elastic zone, in the plastic zone, and the liner, respectively. According to Wang et al. (2008), when $r_{\mathrm{i}} \leq r \leq r_{1}$, there is

$$
Q_{1}=2 \pi k_{1}\left(h_{1}-h_{\mathrm{i}}\right) / \ln \left(r_{1} / r_{\mathrm{i}}\right),
$$

analogously, 


$$
\begin{aligned}
& Q_{\mathrm{p}}=2 \pi k_{\mathrm{p}}\left(h_{\mathrm{p}}-h_{1}\right) / \ln \left(r_{\mathrm{p}} / r_{1}\right), r_{1} \leq r \leq r_{\mathrm{p}}, \\
& Q_{\mathrm{e}}=2 \pi k_{\mathrm{e}}\left(h_{0}-h_{\mathrm{p}}\right) / \ln \left(r_{0} / r_{\mathrm{p}}\right), r_{\mathrm{p}}<r \leq r_{0} .
\end{aligned}
$$

For $Q_{\mathrm{l}} Q_{\mathrm{e}}=Q$, we can obtain:

$$
\begin{aligned}
& h_{1}=\frac{h_{0} \ln \frac{r_{\mathrm{1}}}{r_{\mathrm{i}}}+h_{\mathrm{i}}\left(\frac{k_{\mathrm{l}}}{k_{\mathrm{p}}} \ln \frac{r_{\mathrm{p}}}{r_{\mathrm{1}}}+\frac{k_{1}}{k_{\mathrm{e}}} \ln \frac{r_{0}}{r_{\mathrm{p}}}\right)}{\ln \frac{r_{1}}{r_{\mathrm{i}}}+\frac{k_{1}}{k_{\mathrm{p}}} \ln \frac{r_{\mathrm{p}}}{r_{1}}+\frac{k_{1}}{k_{\mathrm{e}}} \ln \frac{r_{0}}{r_{\mathrm{p}}}}, \\
& h_{\mathrm{p}}=\frac{h_{0}\left(\frac{k_{\mathrm{e}}}{k_{\mathrm{p}}} \ln \frac{r_{\mathrm{p}}}{r_{1}}+\frac{k_{\mathrm{e}}}{k_{1}} \ln \frac{r_{1}}{r_{\mathrm{i}}}\right)+h_{\mathrm{i}} \ln \frac{r_{0}}{r_{\mathrm{p}}}}{\ln \frac{r_{0}}{r_{\mathrm{p}}}+\frac{k_{\mathrm{e}}}{k_{\mathrm{p}}} \ln \frac{r_{\mathrm{p}}}{r_{1}}+\frac{k_{\mathrm{e}}}{k_{1}} \ln \frac{r_{1}}{r_{\mathrm{i}}}}, \\
& Q=\frac{2 \pi k_{\mathrm{e}}\left(h_{0}-h_{\mathrm{i}}\right)}{\ln \frac{r_{0}}{r_{\mathrm{p}}}+\frac{k_{\mathrm{e}}}{k_{\mathrm{p}}} \ln \frac{r_{\mathrm{p}}}{r_{\mathrm{i}}}+\frac{k_{\mathrm{e}}}{k_{1}} \ln \frac{r_{1}}{r_{\mathrm{i}}}}
\end{aligned}
$$

\subsection{Analytical solutions of stresses and displacements}

\subsubsection{Basic equations and boundary conditions}

The seepage force is a body force (Lambe and Whitman, 1969), of which the direction is radial due to the symmetry of the flow. The seepage force per unit volume is

$$
f_{\mathrm{r}}=-\gamma_{\mathrm{w}} \frac{\mathrm{d}(\xi h)}{\mathrm{d} r},
$$

where $\gamma_{\mathrm{w}}$ is the specific weight of the water, $\xi$ is the equivalent surface porosity of the fractured mass. Terzaghi (1936) and Leliavski (1947) determined from field and laboratory studies that $\xi$, the surface porosity, is generally close to unity and always greater than 0.85 .

The solution of a deep tunnel in saturated ground must satisfy the equilibrium equation as follows:

$$
\frac{\mathrm{d} \sigma_{r}}{\mathrm{~d} r}+\frac{\sigma_{r}-\sigma_{\theta}}{r}-\gamma_{\mathrm{w}} \frac{\mathrm{d}(\xi h)}{\mathrm{d} r}=0,
$$

where the subscripts $r$ and $\theta$ denote the radial and tangential directions, respectively. Eq. (10) can be solved with the following boundary conditions:

$$
\begin{aligned}
& \left.\sigma_{r}^{1}\right|_{r=r_{\mathrm{i}}}=\sigma_{\mathrm{i}}, \\
& \left.\sigma_{r}^{\mathrm{e}}\right|_{r=r_{0}}=\sigma_{0}, \\
& \left.\sigma_{r}^{1}\right|_{r=r_{\mathrm{i}}}=\left.\sigma_{r}^{\mathrm{p}}\right|_{r=r_{\mathrm{p}}}=\sigma_{1}, \\
& \left.\sigma_{r}^{\mathrm{p}}\right|_{r=r_{\mathrm{p}}}=\left.\sigma_{r}^{\mathrm{e}}\right|_{r=r_{\mathrm{p}}}=\sigma_{\mathrm{p}}, \\
& \left.u^{1}\right|_{r=r_{\mathrm{i}}}=u_{r_{\mathrm{j}}}^{1}=\left.u^{\mathrm{p}}\right|_{r=r_{\mathrm{i}}}-w=u_{r_{\mathrm{j}}}^{\mathrm{p}}-w, \\
& \left.u^{\mathrm{p}}\right|_{r=r_{\mathrm{p}}}=\left.u^{\mathrm{e}}\right|_{r=r_{\mathrm{p}}}=u_{r_{\mathrm{p}}},
\end{aligned}
$$

where $\sigma_{r}^{1}, \sigma_{\theta}^{1}$, and $u^{1}$ are the radial stress, the tangential stress, and the radial displacement of the liner, respectively; $\sigma_{r}^{\mathrm{p}}, \sigma_{\theta}^{\mathrm{p}}$, and $u^{\mathrm{p}}$ are the radial stress, the tangential stress, and the radial displacement of the ground in the plastic zone, respectively; $\sigma_{r}^{\mathrm{e}}, \sigma_{\theta}^{\mathrm{e}}$, and $u^{\mathrm{e}}$ are the radial stress, the tangential stress, and the radial displacement of the ground in the elastic zone, respectively. $w$ is the gap between the ground and the liner.

\subsubsection{Stresses and displacements of liner}

The analytical solutions of stresses and displacements acting on the liner due to the ground loads and seepage forces are obtained by a theoretical model based on the solutions of $\mathrm{Li}$ (2004):

$$
\begin{gathered}
\sigma_{r}^{1}=K_{1}+K_{2}(1 / r)^{2}-K_{3} \ln r \\
\sigma_{\theta}^{1}=K_{4}-K_{2}(1 / r)^{2}-K_{3} \ln r \\
u_{r}^{1}=K_{5} r-K_{6} r_{\mathrm{i}}^{2} / r-K_{7} r \ln r \\
K_{1}=\frac{\sigma_{1} r_{1}^{2}-\sigma_{\mathrm{i}} r_{\mathrm{i}}^{2}}{r_{\mathrm{i}}^{2}-r_{1}^{2}}+\frac{\gamma_{\mathrm{w}} \xi\left(h_{1}-h_{\mathrm{i}}\right)\left(r_{1}^{2} \ln r_{1}-r_{\mathrm{i}}^{2} \ln r_{\mathrm{i}}\right)}{2\left(1-\mu_{1}\right)\left(r_{\mathrm{i}}^{2}-r_{1}^{2}\right)\left(\ln r_{1}-\ln r_{\mathrm{i}}\right)},(15) \\
K_{2}=\frac{r_{\mathrm{i}}^{2} r_{1}^{2}\left(\sigma_{1}-\sigma_{i}\right)}{\left(r_{1}^{2}-r_{\mathrm{i}}^{2}\right)}+\frac{r_{\mathrm{i}}^{2} r_{1}^{2} \gamma_{\mathrm{w}} \xi\left(h_{1}-h_{\mathrm{i}}\right)}{2\left(1-\mu_{1}\right)\left(r_{1}^{2}-r_{\mathrm{i}}^{2}\right)} \\
K_{3}=\frac{\gamma_{\mathrm{w}} \xi\left(h_{\mathrm{i}}-h_{1}\right)}{2\left(1-\mu_{1}\right)\left(\ln r_{l}-\ln r_{\mathrm{i}}\right)} \\
K_{4}=\frac{\sigma_{1} r_{1}^{2}-\sigma_{\mathrm{i}} r_{\mathrm{i}}^{2}}{r_{\mathrm{i}}^{2}-r_{1}^{2}} \\
+\frac{\gamma_{\mathrm{w}} \xi\left(h_{1}-h_{\mathrm{i}}\right)\left[\left(r_{1}^{2} \ln r_{1}-r_{\mathrm{i}}^{2} \ln r_{\mathrm{i}}\right)-\left(1-2 \mu_{1}\right)\left(r_{\mathrm{i}}^{2}-r_{1}^{2}\right)\right]}{2\left(1-\mu_{1}\right)\left(r_{\mathrm{i}}^{2}-r_{1}^{2}\right)\left(\ln r_{1}-\ln r_{\mathrm{i}}\right)} \\
K_{5}=\frac{-A_{1} r_{\mathrm{i}}^{2}+A_{2} r_{1}^{2}}{r_{1}^{2}-r_{\mathrm{i}}^{2}}
\end{gathered}
$$




$$
\begin{aligned}
& K_{6}=\frac{\left(A_{1}-A_{2}\right) r_{1}^{2}}{\left(1-2 \mu_{1}\right)\left(r_{1}^{2}-r_{\mathrm{i}}^{2}\right)}, \\
& K_{7}=\frac{\left(1+\mu_{1}\right)\left(1-2 \mu_{1}\right) \gamma_{\mathrm{w}} \xi\left(h_{\mathrm{i}}-h_{1}\right)}{2 E_{1}\left(1-\mu_{1}\right)\left(\ln r_{1}-\ln r_{\mathrm{i}}\right)}, \\
& A_{1}=\frac{\left(1+\mu_{1}\right)\left(1-2 \mu_{1}\right)}{E_{1}}\left[\frac{\gamma_{\mathrm{w}} \xi\left(h_{\mathrm{i}}-h_{1}\right)\left(\ln r_{\mathrm{i}}+1-\mu_{1}\right)}{2\left(\ln r_{1}-\ln r_{\mathrm{i}}\right)\left(1-\mu_{1}\right)}-\sigma_{\mathrm{i}}\right],
\end{aligned}
$$

$$
A_{2}=\frac{\left(1+\mu_{1}\right)\left(1-2 \mu_{1}\right)}{E_{1}}\left[\frac{\gamma_{\mathrm{w}} \xi\left(h_{\mathrm{i}}-h_{1}\right)\left(\ln r_{1}+1-\mu_{1}\right)}{2\left(\ln r_{1}-\ln r_{\mathrm{i}}\right)\left(1-\mu_{1}\right)}-\sigma_{1}\right] \text {. }
$$

3.2.3 Stresses and displacements of the ground in the plastic zone

The excavation produces unloading in the radial direction and loading in the tangential direction according to the proposed problem. Therefore, the major principal stress is the tangential stress and the minor principal stress is the radial stress in the plastic zone. At failure, the 2D Mohr-Coulomb criterion can be expressed as $f\left(\sigma_{r}, \sigma_{\theta}\right)=0$, i.e.,

$$
f\left(\sigma_{r}, \sigma_{\theta}\right)=\sigma_{\theta}^{\mathrm{p}}-\frac{1+\sin \varphi_{\mathrm{p}}}{1-\sin \varphi_{\mathrm{p}}} \sigma_{r}^{\mathrm{p}}+\frac{2 c_{\mathrm{p}} \cos \varphi_{\mathrm{p}}}{1-\sin \varphi_{\mathrm{p}}}=0 .
$$

According to the equilibrium equation (Eq. (10)), the boundary conditions (Eqs. (11c) and (11d)), and the failure criterion (Eq. (24)), the ground stresses in the plastic zone are:

$$
\begin{gathered}
\sigma_{r}^{\mathrm{p}}=B-\left(\sigma_{r_{\mathrm{i}}}+B\right)\left(r / r_{1}\right)^{2 \sin \varphi_{\mathrm{p}} /\left(1-\sin \varphi_{\mathrm{p}}\right)} \\
\sigma_{\theta}^{\mathrm{p}}=\frac{1+\sin \varphi_{\mathrm{p}}}{1-\sin \varphi_{\mathrm{p}}}\left[B-\left(\sigma_{r_{\mathrm{r}}}+B\right)\left(\frac{r}{r_{1}}\right)^{\frac{2 \sin \varphi_{\mathrm{p}}}{1-\sin \varphi_{\mathrm{p}}}}\right]-\frac{2 c_{\mathrm{p}} \cos \varphi_{\mathrm{p}}}{1-\sin \varphi_{\mathrm{p}}},
\end{gathered}
$$

where $B$ is a constant and can be expressed as follows:

$$
B=\frac{1-\sin \varphi_{\mathrm{p}}}{2 \sin \varphi_{\mathrm{p}}} \frac{\gamma_{\mathrm{w}} \xi\left(h_{1}-h_{\mathrm{p}}\right)}{\ln r_{\mathrm{p}}-\ln r_{1}}+c_{\mathrm{p}} \cot \varphi_{\mathrm{p}}
$$

Under the axisymmetric plain strain condition, the strains and the displacements are given by

$$
\varepsilon_{r}=\frac{\mathrm{d} u_{r}}{\mathrm{~d} r}, \quad \varepsilon_{\theta}=\frac{u_{r}}{r} .
$$

The compatibility condition is expressed as

$$
\frac{\mathrm{d} \varepsilon_{\theta}}{\mathrm{d} r}=\frac{\varepsilon_{r}-\varepsilon_{\theta}}{r}
$$

Assuming a small strain deformation analysis, the total strains are decomposed into elastic and plastic components, as follows:

$$
\varepsilon_{r}=\varepsilon_{r}^{\mathrm{e}}+\varepsilon_{r}^{\mathrm{p}}, \quad \varepsilon_{\theta}=\varepsilon_{\theta}^{\mathrm{e}}+\varepsilon_{\theta}^{\mathrm{p}},
$$

where the superscripts e and p denote elastic and plastic strains, respectively.

Hooke's law is applied to determine the radial and tangential strains in the elastic region under the plane strain condition:

$$
\left\{\begin{array}{l}
\varepsilon_{r}^{\mathrm{e}}=\left[\sigma_{r}-\sigma_{\theta} \mu_{\mathrm{e}} /\left(1-\mu_{\mathrm{e}}\right)\right]\left(1-\mu_{\mathrm{e}}^{2}\right) / E_{\mathrm{e}}, \\
\varepsilon_{\theta}^{\mathrm{e}}=\left[\left(\sigma_{\theta}-\sigma_{r} \mu_{\mathrm{e}} /\left(1-\mu_{\mathrm{e}}\right)\right]\left(1-\mu_{\mathrm{e}}^{2}\right) / E_{\mathrm{e}},\right.
\end{array}\right.
$$

where $E_{\mathrm{e}}$ and $\mu_{\mathrm{e}}$ denote the elastic modulus and Poisson's ratio, respectively.

The elastic strains in the plastic zone can be readily obtained by substituting the stresses in the plastic zone into Hooke's law (Eq. (31)). The plastic strains in the plastic zone are instead governed by an appropriate flow rule postulated for the yielding behavior. The flow rule of plasticity relating the plastic strain increment $d \varepsilon^{p}$ to the plastic potential $g$ is governed by

$$
\mathrm{d} \varepsilon^{\mathrm{p}}=\mathrm{d} \lambda \frac{\partial g}{\partial \sigma}
$$

where $\mathrm{d} \lambda$ is a non-negative scalar function present throughout the plastic loading process. With the Mohr-Coulomb model, it is often assumed that the plastic potential takes the same form as the yield function while the friction angle is replaced by the dilation angle (which is commonly a smaller angle). The plastic potential can therefore be written as

$$
\begin{aligned}
g\left(\sigma_{r}^{\mathrm{p}}, \sigma_{\theta}^{\mathrm{p}}\right)= & \sigma_{r}^{\mathrm{p}}\left(1+\sin \psi_{\mathrm{p}}\right)-\left(1-\sin \psi_{\mathrm{p}}\right) \sigma_{\theta}^{\mathrm{p}} \\
& -2 c_{\mathrm{p}} \cos \psi_{\mathrm{p}}
\end{aligned}
$$

where $\psi_{\mathrm{p}}$ is the dilation angle. 
By substituting the plastic potential (Eq. (33)) into the flow rule (Eq. (32)), radial and tangential plastic strain increments can be obtained:

$$
\mathrm{d} \varepsilon_{\theta}^{\mathrm{p}}=\mathrm{d} \lambda, \mathrm{d} \varepsilon_{r}^{\mathrm{p}}=-N_{\psi} \mathrm{d} \lambda,
$$

where $\quad N_{\psi}=\left(1+\sin \psi_{\mathrm{p}}\right) /\left(1-\sin \psi_{\mathrm{p}}\right)$. Integration for (Eq. (34)), there is

$$
\varepsilon_{\theta}^{\mathrm{p}}=\lambda, \varepsilon_{r}^{\mathrm{p}}=-N_{\psi} \lambda=-N_{\psi} \varepsilon_{\theta}^{\mathrm{p}} .
$$

By substituting Eqs. (35) and (31) into Eq. (30), then into Eq. (29), a differential equation can be obtained:

$$
\begin{aligned}
\frac{\mathrm{d} \varepsilon_{\theta}^{\mathrm{p}}}{\mathrm{d} r}+ & \frac{N_{\psi}+1}{r} \varepsilon_{\theta}^{\mathrm{p}} \\
= & \frac{4\left(1-\mu_{\mathrm{p}}^{2}\right) \sin \varphi_{\mathrm{p}}\left(\sigma_{1}+B\right) r_{1}}{E_{\mathrm{p}}\left(1-\sin \varphi_{\mathrm{p}}\right)^{2}}\left(\frac{r}{r_{1}}\right)^{\frac{3 \sin \varphi_{\mathrm{p}}-1}{1-\sin \varphi_{\mathrm{p}}}} \\
& +\frac{2\left(1+\mu_{\mathrm{p}}\right)\left(c_{\mathrm{p}} \cos \varphi_{\mathrm{p}}-B \sin \varphi_{\mathrm{p}}\right)}{E_{\mathrm{p}}\left(1-\sin \varphi_{\mathrm{p}}\right)} \frac{1}{r}
\end{aligned}
$$

The solution is

$$
\begin{aligned}
\varepsilon_{\theta}^{\mathrm{p}}= & \frac{4\left(1-\mu_{\mathrm{p}}^{2}\right) \sin \varphi_{\mathrm{p}}\left(\sigma_{1}+B\right)}{E_{\mathrm{p}}\left(1-\sin \varphi_{\mathrm{p}}\right)^{2}\left(N_{\varphi}+N_{\psi}\right)}\left(\frac{r}{r_{1}}\right)^{N_{\varphi}-1} \\
& +\frac{2\left(1+\mu_{\mathrm{p}}\right)\left(c_{\mathrm{p}} \cos \varphi_{\mathrm{p}}-B \sin \varphi_{\mathrm{p}}\right)}{E_{\mathrm{p}}\left(1-\sin \varphi_{\mathrm{p}}\right)\left(1+N_{\psi}\right)}+K_{x} r^{-\left(1+N_{\psi}\right)},
\end{aligned}
$$

where $K_{x}$ is a coefficient which can be determined by the plastic strain at the plastic-elastic interface, $\left.\varepsilon_{\theta}^{\mathrm{p}}\right|_{r=r_{\mathrm{p}}}=0$, as follows:

$$
\begin{aligned}
K_{x}= & -\frac{r_{\mathrm{p}}^{1+N_{\psi}}}{E_{\mathrm{p}}\left(1-\sin \varphi_{\mathrm{p}}\right)} \\
& \times\left[\frac{4\left(1-\mu_{\mathrm{p}}^{2}\right) \sin \varphi_{\mathrm{p}}\left(\sigma_{1}+B\right)}{\left(1-\sin \varphi_{\mathrm{p}}\right)\left(N_{\varphi}+N_{\psi}\right)}\left(\frac{r_{\mathrm{p}}}{r_{1}}\right)^{N_{\varphi}-1}\right. \\
& \left.+\frac{2\left(1+\mu_{\mathrm{p}}\right)\left(c_{\mathrm{p}} \cos \varphi_{\mathrm{p}}-B \sin \varphi_{\mathrm{p}}\right)}{\left(1+N_{\psi}\right)}\right] .
\end{aligned}
$$

By substituting Eq. (38) into Eq. (37), the plastic strain can be written as

$$
\left\{\begin{aligned}
\varepsilon_{r}^{\mathrm{p}}= & -N_{\psi} \varepsilon_{\theta}^{\mathrm{p}}, \\
\varepsilon_{\theta}^{\mathrm{p}}= & \frac{4\left(1-\mu_{\mathrm{p}}^{2}\right) \sin \varphi_{\mathrm{p}}\left(\sigma_{1}+B\right)}{E_{\mathrm{p}}\left(1-\sin \varphi_{\mathrm{p}}\right)^{2}\left(N_{\varphi}+N_{\psi}\right)} \\
& \times\left[\left(\frac{r}{r_{1}}\right)^{N_{\varphi}-1}-\left(\frac{r_{\mathrm{p}}}{r_{1}}\right)^{N_{\varphi}-1}\left(\frac{r_{\mathrm{p}}}{r}\right)^{1+N_{\psi}}\right] \\
& +\frac{2\left(1+\mu_{\mathrm{p}}\right)\left(c_{\mathrm{p}} \cos \varphi_{\mathrm{p}}-B \sin \varphi_{\mathrm{p}}\right)}{E_{\mathrm{p}}\left(1-\sin \varphi_{\mathrm{p}}\right)\left(1+N_{\psi}\right)}\left[1-\left(\frac{r_{\mathrm{p}}}{r}\right)^{1+N_{\psi}}\right] .
\end{aligned}\right.
$$

The tangential strain in the plastic zone can be derived as follows:

$$
\begin{aligned}
& \varepsilon_{\theta}=\frac{1-\mu_{\mathrm{p}}^{2}}{E_{\mathrm{p}}}\left[\left[B-\left(\sigma_{1}+B\right)\left(\frac{r}{r_{1}}\right)^{N_{\varphi}-1}\right]\left(N_{\varphi}-\frac{\mu_{\mathrm{p}}}{1-\mu_{\mathrm{p}}}\right)\right. \\
& +\frac{4 \sin \varphi_{\mathrm{p}}\left(\sigma_{1}+B\right)}{\left(1-\sin \varphi_{\mathrm{p}}\right)^{2}\left(N_{\varphi}+N_{\psi}\right)}\left[\left(\frac{r}{r_{1}}\right)^{N_{\varphi}-1}-\left(\frac{r_{\mathrm{p}}}{r_{1}}\right)^{N_{\varphi}-1}\left(\frac{r_{\mathrm{p}}}{r}\right)^{1+N_{\psi}}\right] \\
& \left.+\frac{2\left(c_{\mathrm{p}} \cos \varphi_{\mathrm{p}}-B \sin \varphi_{\mathrm{p}}\right)}{\left(1-\mu_{\mathrm{p}}\right)\left(1-\sin \varphi_{\mathrm{p}}\right)\left(1+N_{\psi}\right)}\left[1-\left(\frac{r_{\mathrm{p}}}{r}\right)^{1+N_{\psi}}\right]-\frac{2 c_{\mathrm{p}} \cos \varphi_{\mathrm{p}}}{1-\sin \varphi_{\mathrm{p}}}\right] .
\end{aligned}
$$

By substituting Eq. (40) into Eq. (28), the solution of displacements $U^{\mathrm{p}}$ can be written as

$$
\begin{aligned}
& U^{\mathrm{p}}=\frac{r\left(1-\mu_{\mathrm{p}}^{2}\right)}{E_{\mathrm{p}}}\left[\left[B-\left(\sigma_{1}+B\right)\left(\frac{r}{r_{1}}\right)^{N_{\varphi}-1}\right]\left(N_{\varphi}-\frac{\mu_{\mathrm{p}}}{1-\mu_{\mathrm{p}}}\right)\right. \\
& +\frac{4 \sin \varphi_{\mathrm{p}}\left(\sigma_{1}+B\right)}{\left(1-\sin \varphi_{\mathrm{p}}\right)^{2}\left(N_{\varphi}+N_{\psi}\right)}\left[\left(\frac{r}{r_{1}}\right)^{N_{\varphi}-1}-\left(\frac{r_{\mathrm{p}}}{r_{1}}\right)^{N_{\varphi}-1}\left(\frac{r_{\mathrm{p}}}{r}\right)^{1+N_{\psi}}\right] \\
& \left.+\frac{2\left(c_{\mathrm{p}} \cos \varphi_{\mathrm{p}}-B \sin \varphi_{\mathrm{p}}\right)}{\left(1-\mu_{\mathrm{p}}\right)\left(1-\sin \varphi_{\mathrm{p}}\right)\left(1+N_{\psi}\right)}\left[1-\left(\frac{r_{\mathrm{p}}}{r}\right)^{1+N_{\psi}}\right]-\frac{2 c_{\mathrm{p}} \cos \varphi_{\mathrm{p}}}{1-\sin \varphi_{\mathrm{p}}}\right] .
\end{aligned}
$$

Note that for the proposed problem, the initial radial displacement of ground in the plastic zone $u_{0}{ }^{\mathrm{p}}$ induced by the initial stress $\sigma_{0}$ should be subtracted from the total displacement in order to calculate the net displacements induced by tunnelling alone. The expression of $u_{0}^{\mathrm{p}}$ is given by

$$
u_{0}^{\mathrm{p}}=\frac{\left(1+\mu_{\mathrm{p}}\right)\left(1-2 \mu_{\mathrm{p}}\right) \sigma_{0} r}{E_{\mathrm{p}}} .
$$


The expression for displacements due to tunnelling in the plastic zone can be derived as follows:

$$
\begin{aligned}
& u^{\mathrm{p}}=\frac{\left(1-\mu_{\mathrm{p}}^{2}\right) r}{E_{\mathrm{p}}}\left[\left[B-\left(\sigma_{r_{\mathrm{p}}}+B\right)\left(\frac{r}{r_{1}}\right)^{N_{\varphi}-1}\right]\left(N_{\varphi}-\frac{\mu_{\mathrm{p}}}{1-\mu_{\mathrm{p}}}\right)\right. \\
& +\frac{4 \sin \varphi_{\mathrm{p}}\left(\sigma_{r_{\mathrm{p}}}+B\right)}{\left(1-\sin \varphi_{\mathrm{p}}\right)^{2}\left(N_{\varphi}+N_{\psi}\right)}\left[\left(\frac{r}{r_{1}}\right)^{N_{\varphi}-1}-\left(\frac{r_{\mathrm{p}}}{r_{1}}\right)^{N_{\varphi}-1}\left(\frac{r_{\mathrm{p}}}{r}\right)^{1+N_{\psi}}\right] \\
& +\frac{2\left(c_{\mathrm{p}} \cos \varphi_{\mathrm{p}}-B \sin \varphi_{\mathrm{p}}\right)}{\left(1-\mu_{\mathrm{p}}\right)\left(1-\sin \varphi_{\mathrm{p}}\right)\left(1+N_{\psi}\right)}\left[1-\left(\frac{r_{\mathrm{p}}}{r}\right)^{1+N_{\psi}}\right] \\
& \left.-\frac{\left(1-2 \mu_{\mathrm{p}}\right) \sigma_{0}}{1-\mu_{\mathrm{p}}}-\frac{2 c_{\mathrm{p}} \cos \varphi_{\mathrm{p}}}{1-\sin \varphi_{\mathrm{p}}}\right] .
\end{aligned}
$$

3.2.4 Stresses and displacements of ground in the elastic zone

Note that the initial radial displacement of ground in the elastic zone $u_{0}{ }^{\mathrm{e}}$ induced by the initial stress $\sigma_{0}$ should be subtracted from the total displacement to calculate the net displacements induced by tunnelling alone (Fang et al., 2013). The expression of $u_{0}{ }^{\mathrm{e}}$ is given by

$$
\begin{aligned}
u_{0}^{\mathrm{e}}= & \frac{\left(1+\mu_{\mathrm{p}}\right)\left(1-2 \mu_{\mathrm{p}}\right) \sigma_{0} r_{\mathrm{p}}}{E_{p}} \\
& +\frac{\left(1+\mu_{\mathrm{e}}\right)\left(1-2 \mu_{\mathrm{e}}\right) \sigma_{0}\left(r-r_{\mathrm{p}}\right)}{E_{\mathrm{e}}} .
\end{aligned}
$$

The ground stresses and displacements in the elastic zone can be derived by using the same methods as calculating the distributions of liner stresses and displacements. Therefore, the solutions can be written as

$$
\begin{gathered}
\sigma_{r}^{\mathrm{e}}=K_{1}^{\prime}+K_{2}^{\prime}(1 / r)^{2}-K_{3}^{\prime} \ln r \\
\sigma_{\theta}^{\mathrm{e}}=K_{1}^{\prime}-K_{2}^{\prime}(1 / r)^{2}-K_{3}^{\prime} \ln r \\
u^{\mathrm{e}}=K_{5}^{\prime} r-K_{6}^{\prime} \frac{r_{\mathrm{p}}^{2}}{r}-K_{7}^{\prime} r \ln r+\frac{\left(1+\mu_{\mathrm{p}}\right)\left(1-2 \mu_{\mathrm{p}}\right) \sigma_{0} r_{\mathrm{p}}}{E_{\mathrm{p}}} \\
+\frac{\left(1+\mu_{\mathrm{e}}\right)\left(1-2 \mu_{\mathrm{e}}\right) \sigma_{0}\left(r-r_{\mathrm{p}}\right)}{E_{\mathrm{e}}}
\end{gathered}
$$

where $K_{1}^{\prime}-K_{7}^{\prime}$ have the same expressions as $K_{1}-K_{7}$ but replacing $r_{\mathrm{i}}, r_{\mathrm{l}}, h_{\mathrm{i}}, h_{\mathrm{l}}, \mu_{\mathrm{l}}, \sigma_{\mathrm{i}}$, and $\sigma_{\mathrm{l}}$ by $r_{\mathrm{p}}, r_{0}, h_{\mathrm{p}}, h_{0}$, $\mu_{\mathrm{e}}, \sigma_{\mathrm{p}}$, and $\sigma_{0}$, respectively.

\subsubsection{Expressions of $\sigma_{r_{\mathrm{i}}}, \sigma_{r_{\mathrm{p}}}$, and $r_{\mathrm{p}}$}

The solutions in this study must satisfy the equilibrium equations, the strain compatibility equations, and the boundary conditions (Eqs. (11c) $-(11 \mathrm{f}))$.

According to Eqs. (11c), (11d), and (11f), we can obtain

$$
\begin{aligned}
\sigma_{1}= & {\left[B-\frac{\frac{u_{r_{\mathrm{p}}} E_{\mathrm{p}}}{\left(1-\mu_{\mathrm{p}}^{2}\right) r_{\mathrm{p}}}+\frac{2 c_{\mathrm{p}} \cos \varphi_{\mathrm{p}}}{1-\sin \varphi_{\mathrm{p}}}}{N_{\varphi}-\frac{\mu_{\mathrm{p}}}{1-\mu_{\mathrm{p}}}}\right]\left(\frac{r_{1}}{r_{\mathrm{p}}}\right)^{N_{\varphi}-1}-B, \quad(48) } \\
\sigma_{\mathrm{p}}= & {\left[\frac{E_{\mathrm{p}}\left[\left(1-2 \mu_{\mathrm{e}}\right) r_{\mathrm{p}}^{2}-r_{0}^{2}\right] A_{3}+2 E_{\mathrm{p}} \mu_{\mathrm{e}} r_{0}^{2} A_{2}^{\prime}}{\left(1-\mu_{\mathrm{p}}^{2}\right)\left(1-2 \mu_{\mathrm{e}}\right)\left(r_{0}^{2}-r_{\mathrm{p}}^{2}\right)}\right.} \\
& \left.+\frac{E_{\mathrm{p}} K_{7}^{\prime} \ln r_{\mathrm{p}}}{1-\mu_{\mathrm{p}}^{2}}-\frac{2 c_{\mathrm{p}} \cos \varphi_{\mathrm{p}}}{1-\sin \varphi_{\mathrm{p}}}\right] \\
& /\left(N_{\varphi}-\frac{\mu_{\mathrm{p}}}{1-\mu_{\mathrm{p}}}+\frac{E_{\mathrm{p}}\left(1+\mu_{\mathrm{e}}\right)\left[\left(1-2 \mu_{\mathrm{e}}\right) r_{\mathrm{p}}^{2}+r_{0}^{2}\right]}{E_{\mathrm{e}}\left(1-\mu_{\mathrm{p}}^{2}\right)\left(r_{0}^{2}-r_{\mathrm{p}}^{2}\right)}\right],
\end{aligned}
$$

where

$$
\begin{aligned}
A_{3}= & \frac{\left(1+\mu_{\mathrm{e}}\right)\left(1-2 \mu_{\mathrm{e}}\right) \gamma_{\mathrm{w}} \xi\left(h_{\mathrm{p}}-h_{0}\right)\left(\ln r_{\mathrm{p}}+1-\mu_{\mathrm{e}}\right)}{2 E_{\mathrm{e}}\left(\ln r_{0}-\ln r_{\mathrm{p}}\right)\left(1-\mu_{\mathrm{e}}\right)}, \\
A_{2}^{\prime}= & \frac{\left(1+\mu_{\mathrm{e}}\right)\left(1-2 \mu_{\mathrm{e}}\right)}{E_{\mathrm{e}}} \\
& \times\left[\frac{\gamma_{\mathrm{w}} \xi\left(h_{\mathrm{p}}-h_{0}\right)\left(\ln r_{0}+1-\mu_{\mathrm{e}}\right)}{2\left(\ln r_{0}-\ln r_{\mathrm{p}}\right)\left(1-\mu_{\mathrm{e}}\right)}-\sigma_{0}\right] .
\end{aligned}
$$

By substituting Eqs. (48) and (49) into Eq. (11e), a transcendental equation can be obtained to find the value of $r_{\mathrm{p}}$. By substituting the value of $r_{\mathrm{p}}$ into Eq. (6) and Eq. (7), the values of $h_{1}$ and $h_{\mathrm{p}}$ can be obtained. Then, $\left(\sigma_{r}{ }^{1}, \sigma_{\theta}{ }^{1}, u^{\mathrm{l}}\right),\left({\sigma_{r}}^{\mathrm{p}}, \sigma_{\theta}{ }^{\mathrm{p}}, u^{\mathrm{p}}\right)$, and $\left(\sigma_{r}{ }^{\mathrm{e}}, \sigma_{\theta}{ }^{\mathrm{e}}, u^{\mathrm{e}}\right)$ can be obtained, and so forth.

\section{Validation of the analytical solutions}

\subsection{Parameters used in validation}

To validate the analytical model, the results of the analytical model are compared with those 
obtained from numerical computations. A MATLAB program is used to carry out the computations for the analytical model. The numerical computations are carried out by using a 3D finite difference code FLAC $^{3 \mathrm{D}}$ (Itasca Consulting Group, Inc., 1997; 2002) which can address 3D continuum problems with coupled groundwater flow. This comparison is intended to validate the solutions. A group of typical parameter values are employed, $w=0,7.5,15,23$, $30.5,38,46,53.5,61,68.5$, and 76.5 (unit: $\mathrm{mm}$ ), varied to simulate different stress releases before liner construction, and the others are shown in Table 1. Only a quarter of the geometry needs to be modeled due to symmetry. The geometry of the mesh and the boundary conditions are shown in Fig. 2. The normal velocities of the gridpoints along the bottom, vertical lateral, front and back boundary planes are fixed to be zero (Fang et al., 2013).

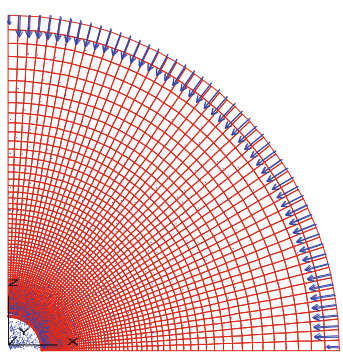

(a)

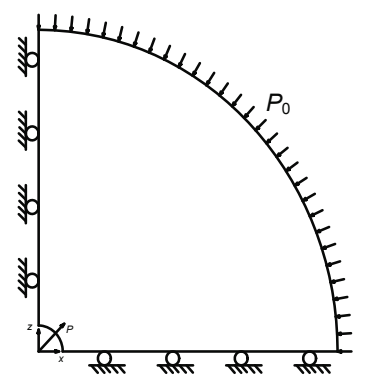

(b)
Fig. 2 Calculation model (a) and boundary conditions (b)

Table 1 Parameters used in the validation

\begin{tabular}{cc||cc}
\hline Parameter & value & Parameter & value \\
\hline$r_{\mathrm{i}}(\mathrm{m})$ & 5 & $\xi$ & 1 \\
$r_{1}(\mathrm{~m})$ & 5.3 & $\mu_{\mathrm{l}}$ & 0.2 \\
$r_{0}(\mathrm{~m})$ & 100 & $\mu_{\mathrm{p}}$ & 0.35 \\
$h_{\mathrm{i}}(\mathrm{m})$ & 0 & $\mu_{\mathrm{e}}$ & 0.35 \\
$h_{0}(\mathrm{~m})$ & 80 & $\varphi_{\mathrm{p}}$ & 40 \\
$\sigma_{\mathrm{i}}(\mathrm{MPa})$ & 0 & $\psi_{\mathrm{p}}$ & 0 \\
$\sigma_{0}(\mathrm{MPa})$ & 2 & $k_{\mathrm{l}}(\mathrm{m} / \mathrm{s})$ & $1 \times 10^{-8}$ \\
$E_{1}(\mathrm{GPa})$ & 10 & $k_{\mathrm{p}}(\mathrm{m} / \mathrm{s})$ & $1 \times 10^{-6}$ \\
$E_{\mathrm{p}}(\mathrm{GPa})$ & 1 & $k_{\mathrm{e}}(\mathrm{m} / \mathrm{s})$ & $1 \times 10^{-6}$ \\
$E_{\mathrm{e}}(\mathrm{GPa})$ & 1 & $c_{\mathrm{p}}(\mathrm{kPa})$ & 100 \\
\hline
\end{tabular}

\subsection{Relationship between $r_{\mathrm{p}}-r_{1}$ and $w$}

The results of the calculations for the relationship between $r_{\mathrm{p}}-r_{1}$ and $w$ are given in Fig. 3. It is clear from the plot that the solutions of the study and FLAC $^{3 \mathrm{D}}$ match well. All illustrative comparisons of the solution and the numerical results show little effect on the FLAC ${ }^{3 \mathrm{D}}$ boundary constraints along the edges of the mesh. The yield zone radius increases significantly with the increase of $w$. This shows that the earlier the liner is carried out, the more significant the decreases in the plastic zone.

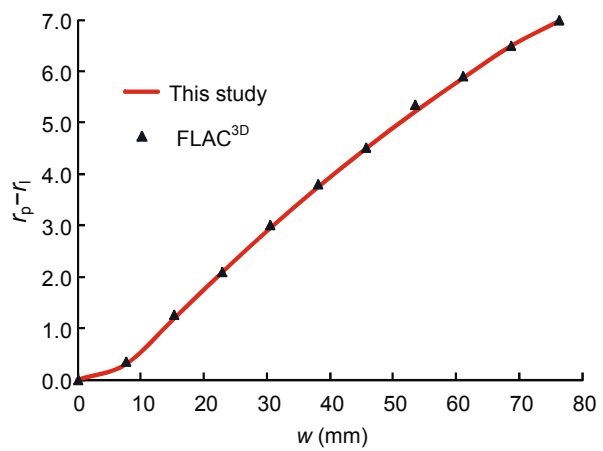

Fig. 3 Relationship between $r_{\mathrm{p}}-r_{1}$ and $w$

\subsection{Results of the calculation}

Results of the calculation for the stresses and displacements are given in Figs. 4 and 5. The solutions of the study and FLAC ${ }^{3 \mathrm{D}}$ are matched well.

From the relationship between $\sigma_{r_{1}} / \sigma_{0}$ and $w$ in Fig. 4, it is clear that contrary to $r_{\mathrm{p}}$, the effective radial stress at the ground-liner interface, $\sigma_{r_{1}}$ decreases significantly with the increase of $w$, and $\sigma_{r} \approx 0$ when $w=76.5 \mathrm{~mm}$. This shows that the earlier the liner is carried out, the more significant will be the increase in the liner stress. Thus, appropriate time for the liner construction should be selected for a safe and economical design.

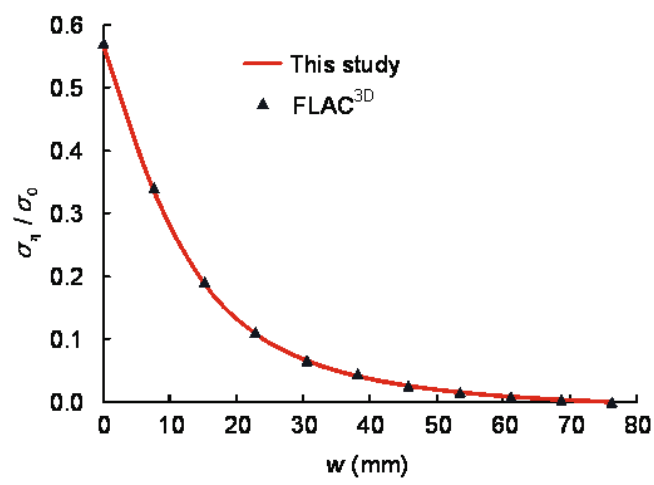

Fig. 4 Relationship between $\sigma_{r_{1}} / \sigma_{0}$ and $w$

Fig. 5 shows stresses distributions around the tunnel when $w=15 \mathrm{~mm}$. We can find that: (1) with the increase of distance from the tunnel centerline, the 
radial stress increases until it ceases to the in site stress, and yet the tangential stress in the ground increases to the maximum equaling two times that of the in site stress and then decreases until it ceases to the in site stress; (2) The tangential stress in the liner decreases with the increase of the distance from the tunnel centerline, and the discontinuity appears at the ground-liner interface because of different elastic moduli between the ground and liner.

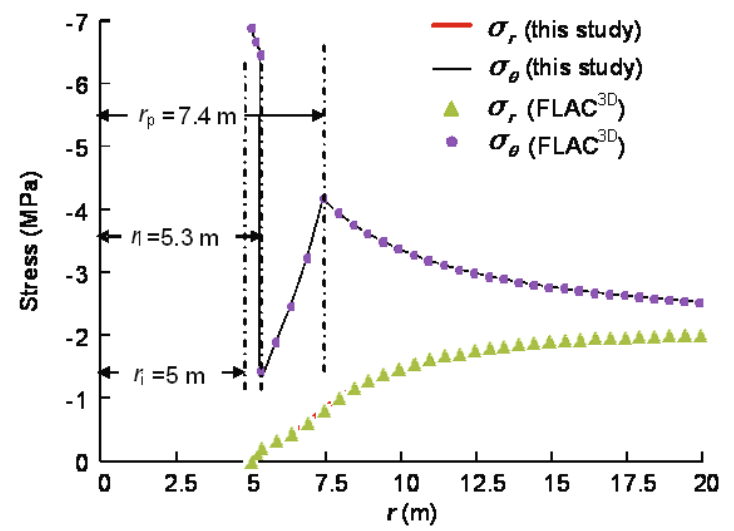

Fig. 5 Stress distributions around the tunnel when $w=$ $15 \mathrm{~mm}$

\section{Conclusions}

The analytical solutions presented in this paper expand and complete previous studies, in that we have now obtained complete analytical solutions for a deep tunnel in saturated ground. Although the analytical solutions are valid only for cases under the given assumptions, it appears to be useful for a preliminary design of deep tunnels under high water levels to predict the water pressure, stresses and displacement distributions around the tunnel. Stresses and displacement distributions using the proposed analytical solutions are compared to the numerical solution of FLAC ${ }^{3 \mathrm{D}}$, which appears to match well. For more complicated scenarios, a numerical model would be flexible. Nevertheless, the theoretical expressions derived in this study can be used in validating the numerical models.

\section{References}

Arjnoi, P., Jeong J.H., Kim, C.Y., et al., 2009. Effect of drainage conditions on porewater pressure distributions and lining stressed in drained tunnels. Tunnelling and Underground Space Technology, 24(4):376-389. [doi:10. 1016/j.tust.2008.10.006]
Bear, J., 1972. Dynamics of Fluids in Porous Media. American Elsevier Publishing Company, New York.

Bobet, A., 2001. Analytical solutions for shallow tunnels in saturated ground. Journal of Engineering Mechanics, 127(12):1258-1266. [doi:10.1061/(ASCE)0733-9399 (2001)127:12(1258)]

Bobet, A., 2003. Effect of pore water pressure on tunnel support during static and seismic loading. Tunnelling and Underground Space Technology, 18(4):377-393. [doi:10. 1016/S0886-7798(03)00008-7]

Brown, E.T., Bray, J.W., Ladanyi, B., et al., 1983. Ground response curves for rock tunnels. Journal of Geotechnical Engineering, 109(1):15-39. [doi:10.1061/(ASCE)07339410(1983)109:1(15)]

Carranza-Torres, C., Fairhurst, C., 2000. Application of the convergence-confinement method of tunnel design to rock-masses that satisfy the Hoek-Brown failure criterion. Tunnelling and Underground Space Technology, 15(2): 187-213. [doi:10.1016/S0886-7798(00)00046-8]

Fang, Q., Zhang, D.L., Zhou, P., et al., 2013. Ground reaction curves for deep circular tunnels considering the effect of ground reinforcement. International Journal of Rock Mechanics \& Mining Sciences, 60:401-412. [doi:10. 1016/j.ijrmms.2013.01.003]

Fenner, R., 1938. Undersuchungen zur Erkenntnis des Gebirgsdruckes. Gluckauf, 74:681-695, 705-715 (in German)

González-Nicieza, C., Álvarez-Vigil, Menéndez-Díaz, A.E., González-Palacio, A.C., 2008. Influence of the depth and shape of a tunnel in the application of the convergenceconfinement method. Tunnelling and Underground Space Technology, 23(1):25-37. [doi:10.1016/j.tust.2006.12. 001]

Han, J.X., Li, S.C., Li, S.C., et al., 2013. A procedure of strain-softening model for elasto-plastic analysis of a circular opening considering elasto-plastic coupling. Tunnelling and Underground Space Technology, 37: 128-134. [doi:10.1016/j.tust.2013.04.001]

Huangfu, M., Wang, M.S., Tan, Z.S., et al., 2010. Analytical solutions for steady seepage into an underwater circular tunnel. Tunnelling and Underground Space Technology, 25(4):391-396. [doi:10.1016/j.tust.2010.02.002]

Itasca Consulting Group, Inc., 1997. Fast Language Analysis of Continua Three Dimensions.

Itasca Consulting Group, Inc., 2002. FLAC-Fast Lagrangian Analysis of Continua, Version 4.0. Minneapolis.

Lambe, T.W., Whitman, R.V., 1969. Soil Mechanics. Wiley, NewYork.

Lee, I.M., Nam, S.W., 2001. The study of seepage forces acting on the tunnel liner and tunnel face in shallow tunnels. Tunnelling and Underground Space Technology, 16(1):31-40. [doi:10.1016/S0886-7798(01)00028-1]

Lee, I.M., Kim, J.H., Reddi, L.N., 2000. Permeability reduction model of soil-geotextile system induced by clogging. Journal of the Korean Geotechnical Society, 16(4): 107-116. 
Li, P.F., 2011. Study on Stability Analysis and Control of Subsea Tunnel Surrounding Rock. PhD Thesis, Beijing Jiaotong University, Beijing, China.

Li, Z.L., Ren, Q.W., Wang, Y.H., 2004. Elasto-plastic analytical solution of deep-buried circle tunnel considering fluid flow field. Chinese Journal of Rock Mechanics and Engineering, 23:1291-1295.

Liolios, P.A., Exadaktylos, G.E., 2006. A solution of steadystate fluid flow in multiply fractures isotropic porous media. International Journal of Solids and Structures, 43(13):3960-3982. [doi:10.1016/j.ijsolstr.2005.03.021]

Liu, C.X., Yang, L.D., Li, P., 2009. Elastic-plastic analytical solution of deep buried circle tunnel considering stress redistribution. Engineering Mechanics, 26:16-20.

Lu, X.C., Xu, J.Y., 2009. Elastic-plastic solution for subsea circular tunnel under the influence of seepage field. Engineering Mechanics, 26:216-221.

Nam, S.W., Bobet, A., 2006. Liner stresses in deep tunnels below the water table. Tunnelling and Underground Space Technology, 21(6):626-635. [doi:10.1016/j.tust. 2005.11.004]

Oreste, P.P., 2003a. Analysis of structural interaction in tunnels using the convergence-confinement approach. Tunnelling and Underground Space Technology, 18(4): 347-363. [doi:10.1016/S0886-7798(03)00004-X]

Oreste, P.P., 2003b. A procedure for determining the reaction curve of shotcrete lining considering transient conditions. Rock Mechanics and Rock Engineering, 36(3):209-236.

Schweiger, H.F., Pottler, R.K., Steiner, H., 1991. Effect of seepage forces on the shotcrete liner of a large undersea cavern. Computer Methods and Advances in Geomechanics, p.1503-1508.

Sharan, S.K., 2005. Exact and approximate solutions for displacements around circular openings in elastic-brittleplastic Hoek-Brown rock. International Journal of Rock Mechanics and Mining Sciences, 42(4):542-549. [doi:10.1016/j.ijrmms.2005.03.019]

Terzaghi, K., 1936. Simple tests determine hydrostatic uplift. Engineering News Record, 116(25):872-875.

Wang, X.Y., Tan, Z.S., Wang, M.S., et al., 2008. Theoretical and experimental study of external water pressure on tunnel liner in controlled drainage under high water level. Tunnelling and Underground Space Technology, 23(5): 552-560. [doi:10.1016/j.tust.2007.10.004]

\section{中文概要：}

\section{本文题目: 深埋圆形富水隧道应力与位移的弹塑性解}

Analytical solutions of stresses and displacements for deep circular tunnels with liners in saturated ground

研究目的：推导获得深埋圆形富水隧道应力场与位移场分布的弹塑性解析解。

创新要点: 基于弹性力学厚壁圆筒受均布压力的拉姆解答和 Mohr-Coulomb 屈服条件, 推导了考虑渗流 作用和应力释放时含祄砌深埋隧道的弹塑性解, 并采用 $\mathrm{FLAC}^{3 \mathrm{D}}$ 有限差分程序验证了其正确 性。

研究方法: 通过理论分析建立考虑渗流作用和应力释放的含衬砌深埋圆形隧道的解析模型 (图 1), 然 后推导了基于 Mohr-Coulomb 屈服准则的隧道围岩与祄砌渗流场、位移场和应力场计算的弹 塑性解析公式, 并通过数值模拟程序（图 2) 验证了推导公式的正确性。

重要结论: 基于前人研究基础, 推导获得了深埋富水隧道应力与位移场分布的理论解析解, 并通过数值 模拟方法验证了其正确性。该解析解一方面可以用于深埋高水头隧道的预设计, 如预测隧道 周围的水压力、应力场和位移场分布规律, 另一方面可用于校核大型复杂数值模型的正确性。 